\title{
An experimental investigation of the 'match/ mismatch' hypothesis using larval Atlantic cod
}

\author{
Vytenis Gotceitas*, Velmurugu Puvanendran, Leslie L. Leader**, Joseph A. Brown \\ Ocean Sciences Centre, Memorial University of Newioundland, St. John's, Newfoundland, Canada A1C 5S7
}

\begin{abstract}
The match/mismatch hypothesis suggests that the degree of overlap between larval fish and their prey affects larval growth, survival and recruitment. For example, some fish species have a relatively fixed spawning period while peak production of their food varies yearly, depending on abiotic factors, creating a match or mismatch between the two. In this study, we investigated the influence of a match or mismatch on growth of cod (Gadus morhua) larvae. Larvae were exposed to 1 of 5 different food treatments: (1) high food (HF) (match); (2) low food (LF), (3) HF then LF (HF-LF), and (4) LF then HF (LF-HF) (2, 3 \& 4 mismatch); and (5) no food (NF) (complete mismatch). In treatments including a switch in food level, the switch took place on Day 11 post-hatch. Larvae were sampled every $5 \mathrm{~d}$, and standard length, body depth, dry weight, and gut fullness recorded. Specific growth rate (\% dry wt $\mathrm{d}^{-1}$ ) of larvae reared under the different food treatments was calculated. The experiment was repeated to examine the influence of Treatments 1 to 4 on survival of larval cod. All larvae in the NF treatment died by Day 20 post-hatch. Larvae under HF conditions were significantly larger than those in all other treatments by Day 20 post-hatch, while at Day 35, there was no difference between larvae from the HF and LF-HF treatments. Larvae under the LF-HF treatment were significantly larger than those from the HF-LF and LF treatments by Day 30 post-hatch. There was no significant difference in size between larvae from the HF-LF and LF treatments throughout the experiment. Specific growth rate was highest when larvae were exposed to a HF level. A switch between LF and HF resulted in a significant increase in specific growth rate in the LF-HF treatment and decrease in the HF-LF treatment. The number of larvae surviving to Day 35 post-hatch, and through to metamorphosis, was highest for the HF treatment, followed by the LF-HF, HF-LF, and LF treatments. Our results suggest that a mismatch and its timing can significantly influence the growth and survival of cod larvae.
\end{abstract}

KEY WORDS: Atlantic cod larvae - Match/mismatch hypothesis - Gadus morhua - Feeding - Growth · Survival

\section{INTRODUCTION}

Faster growth through the larval stage has been suggested as an important factor contributing to increased survival in fish (Blaxter 1986, Houde 1987, Miller et al. 1988). This relationship is most likely attributable to an increase in the ability of larvae to both acquire food and avoid predation with increasing size and level of development (Blaxter 1986). This being the case, factors influencing prey availability for larval fish should have a direct effect on recruitment to the adult population.

\footnotetext{
•E-mail:vytenis@kean.ucs.mun.ca

-Present address: Vancouver Aquarium, PO Box 3232,

Vancouver, British Columbia, Canada V6B 3 X8
}

The 'match/mismatch' hypothesis has been proposed as one explanation for the variability in recruitment observed in many fish stocks (Cushing 1990). The hypothesis relates recruitment success to variability in the survival of larval fish as a result of annual variation in temporal and/or spatial overlap between larvae and their prey. The underlying assumptions of the hypothesis are that (1) spawning in fish, and, therefore, time of peak abundance of larvae, is fairly constant year to year, while (2) the timing of the annual peak in primary production and reproduction in zooplankton varies on a yearly basis depending on various environmental conditions. Water temperature appears to be an important abiotic factor controlling timing of the production of prey for larvae of various temperate marine fishes (Cushing 1990). As such, a temporal 
'mismatch' between the peak abundance of larval fish and their prey may occur during abnormally cold or warm years. Support for the match/mismatch hypothesis comes from various field studies (e.g. Ellertsen et al. 1989. Fortier \& Gagne 1990) examining the temporal and spatial overlap between larval fish and their prey. However, although the influence of a 'match' or 'mismatch' between larval fish and their prey is assumed to affect the growth and survival of the larvae, no study has addressed this directly. Therefore, in this study, we exposed larval Atlantic cod Gadus morhua to conditions simulating a match and mismatch with their food source and monitored larval growth and survival.

\section{MATERIALS AND METHODS}

Experimental cod. Larval cod were obtained from eggs collected from a laboratory brood stock. Eggs were spawned 'naturally' within the holding tanks, and all larvae used in this experiment came from eggs collected during a single $24 \mathrm{~h}$ period. Eggs were incubated at $7^{\circ} \mathrm{C}$. Larvae were transferred to experimental tanks when $50 \%$ of the eggs had hatched (Day 0 posthatch for this experiment)

Atlantic cod was chosen as our experimental fish because various field studies suggest that the match/ mismatch hypothesis may apply to this species (Runge 1988, Ellertsen et al. 1989, Cushing 1990, Mertz \& Myers 1994). Several populations of Atlantic cod spawn within a fixed time period annually and are highly dependent on the early life-stages of a single zooplankter (e.g. Calanus finmarchicus). The time of reproduction in $C$. finmarchicus varies in response to water temperature. As a result of this 'strong link' (as in Runge 1988) between the production of $C$. finmarchicus and larval cod, warm or cold years could result in a mismatch between peak larval abundance and abundance of prey.

Experimental design. Experiments were conducted in nine 60 I hexagonal glass tanks. Tanks were housed under $24 \mathrm{~h}$ light. While this is Ionger than that typically experienced (i.e. 14 to $16 \mathrm{~h}$ of light) by cod larvae around Newfoundland, Canada, 24 h was used to optimize larval growth and survival under laboratory conditions (e.g. Duray \& Kohno 1988). Water temperature in the tanks was maintained at 7 to $9^{\circ} \mathrm{C}$. There was no flow of water through the tanks between Days 0 and 7 post-hatch. Between Days 8 and 21, water was supplied to each tank at a rate of $100 \mathrm{ml} \mathrm{min}{ }^{-1}$. This was increased to $400 \mathrm{ml} \mathrm{min}{ }^{-1}$ starting on Day 22 posthatch and was maintained at this level until the end of the experiment. This regime of water exchange was based on methods used by other researchers (Howell 1984) and was employed to minimize the disturbance and maximize the likelihood of survival of our cod larvae (preliminary experiments, authors' pers. obs.). Water was introduced at the bottom of each tank. Circulation and aeration of the water in each tank were maintained by a constant flow of air into each tank.

Each tank was stocked on Day 0 post-hatch with a density of 30 cod larvae $\mathrm{l}^{-1}$. This stocking density was chosen based on earlier attempts at rearing cod larvae in our laboratory. Larvae within each tank were exposed to 1 of 5 prey treatments: (1) high food throughout (HF) (match); (2) low food throughout (LF), (3) HF for the first $10 \mathrm{~d}$ post-hatch then LF (HF-LF), and (4) LF for the first $10 \mathrm{~d}$ post-hatch then $\operatorname{HF}$ (LF-HF) $(2,3$ \& 4 mismatch); and (5) no food (NF) (control or complete mismatch). Two tanks each were exposed to the prey treatments HF, LF, HF-LF and LF-HF, and one to NF. Timing of the switch between HF and LF, and vice versa, was chosen to reflect a point approximately midway between the time of first feeding (i.e. Days 5 to 7 post-hatch) and 'the point of no return' for cod larvae reared in our laboratory (i.e. all larvae not feeding by this time die; Days 15 to 18 post-hatch). Food was present in the appropriate tanks from Day 0 post-hatch.

In this experiment the HF level was set at 4000 prey $\mathrm{l}^{-1}$, and the L.F level at 500 prey $\mathrm{l}^{-1}$. Prey densities and types (see below) used in this study were not chosen to necessarily represent field conditions, but to favour sufficient survival of larvae among the different food treatments to allow subsequent comparisons to be made. Based on earlier experiments (authors' unpubl. data), the densities chosen represent those that result in maximum survival ( $\mathrm{HF}$ ) and those that insure that at least some (LF) cod larvae survive through to metamorphosis under our laboratory conditions. Through the use of these prey densities, our experiment addressed the effects of variation in food availability (i.e. match vs mismatch) on the growth and survival of larval cod. Since the match/mismatch hypothesis assumes that larval fish experience low or high food conditions in the field, we feel our experiment provided insight into the effects a match or mismatch between larvae and their prey might have on larval growth and survival, regardless of what the actual densities of larvae and prey representing match and mismatch conditions in the field may be. Finally, while prey and larval densities chosen for this experiment were substantially higher than values reported from field studies (Ellertsen et al. 1989, Thompson \& Harrop 1991, Brander 1992), on a prey/larva basis (i.e. LF: 16.7 prey/larva; HF: 133.3 prey/larva), our values are actually lower than the estimated daily requirement for growth and survival of individual cod larvae at $8.5^{\circ} \mathrm{C}$ based on field data (i.e. 161 to 196 copepods $d^{-1}$ for cod larvae from 4 to $12.5 \mathrm{~mm}$ in length, respectively; Thompson \& Harrop 1991). In addition, while reported field densi- 
ties of larval fish and their prey are typically low relative to those used in most laboratory studies, the question remains as to the potential failure by field studies to provide accurate estimates of the prey densities to which larval fish are actually exposed (i.e. larvae in patches of prey) (Hunter \& Thomas 1974, Frank 1988)

A combination of prey sizes was used to insure that prey of a suitable size would be available to the larvae as they grew. All prey were cultured in the laboratory. For the first $6 \mathrm{~d}$ post-hatch, enriched rotifers (Brachionus sp.) were the only prey present. From Days 7 to 14 post-hatch, larvae were offered a combination of enriched rotifers and Artemia nauplii (Artemia franciscana) at a ratio of 10:1, respectively. From Days 15 to 28 post-hatch, enriched Artemia nauplii were provided so as to establish an equal ratio of Artemia to rotifers; finally, starting on Day 29 post-hatch, the only prey presented was enriched Artemia nauplii.

To insure that the appropriate level of food was present and maintained in each tank, a $10 \mathrm{ml}$ sample of water was taken once a day from each experimental tank and the number of prey items in each sample counted under a dissecting microscope. The depth within the tank at which this sample was taken varied from day to day. Prey were added to tanks as necessary to maintain pre-set levels.

Cod larvae were sampled from each tank at $5 \mathrm{~d}$ intervals, starting with Day 0 post-hatch (i.e. the day larvae were introduced into the experimental tanks). From each tank 5 larvae were randomly selected and the following morphometric measurements recorded: (1) standard length (SL) in $m m$, (2) body depth at the anus (BD) in $\mathrm{mm}$, and (3) dry weight (DWT) in $\mathrm{mg}$. Body measurements of individual larvae were taken using a dissecting microscope equipped with an eyepiece micrometer. Larvae were anaesthetized using a $0.0005 \mathrm{ppm}$ solution of tricaine methanesulfonate prior to measuring. After body measurements were taken, individual larvae were placed in a pre-weighed aluminium foil container and then in an oven set at $105^{\circ} \mathrm{C}$ for $24 \mathrm{~h}$. Larvae were then weighed to the nearest $0.0001 \mathrm{mg}$ using an electronic micro-balance. Sampling of larvae was terminated at Day 35 post-hatch because insufficient larvae remained in some of the food treatments to warrant continuing the experiment through to the next sampling day.

Specific growth rate (SGR) of cod larvae was calculated from the formula:

$$
\mathrm{SGR}=\left(\ln \mathrm{DWT}_{t_{2}}-\ln \mathrm{DWT}_{t_{1}}\right) \times\left(t_{2}-t_{1}\right)^{-1} \times 100 .
$$

where $D W T_{t 1}$ and $D W T_{t 2}$ are mean dry weights of cod larvae at times $t_{1}$ and $t_{2}$, respectively (Hawkins et al. 1985, Buckley et al. 1987, Cui \& Liu 1990). SGR was calculated for larvae from all 5 food treatments for the time interval 0 to $10 \mathrm{~d}$ post-hatch and for all food treat- ments, except NF, for the interval 10 to $35 \mathrm{~d}$ post-hatch. These intervals were chosen to facilitate the comparison of SGR before and after the switching in food levels in the LF-HF and HF-LF treatments.

Each larva sampled was also examined for the presence of prey in its gut. This was done by examining individual larvae under the dissecting microscope. Gut fullness was expressed as the proportion of the gut containing food (i.e. empty to full gut: 0.0 to 1.0 respectively).

To investigate the influence of the HF, LF, LF-HF, and HF-LF treatments on survival of cod larvae, the experiment described above was repeated, only no larvae were sampled. At Day 35 post-hatch, the number of live larvae in both tanks of each food treatment were counted by visual inspection. This was done independently by 2 inspectors to insure an unbiased count. Discrepancies between inspectors in the total number of larvae counted varied from no difference for treatments LF and HF-LF to 3 to 5 larvae for the HF and LF$\mathrm{HF}$ treatments at $35 \mathrm{~d}$ post-hatch. Finally, the number of larvae metamorphosing into juveniles was recorded for each food treatment. This experiment was terminated at Day 50 post-hatch because all larvae in the LF treatment were either dead or had metamorphosed into juveniles

Data analysis. The effects of food treatment and larval age (i.e. days post-hatch) on larval SL, BD, DWT, SGR and gut fullness were analysed using analysis of variance (Proc GLM; SAS Institute 1988). All data were checked for normality, and SGR values were $\log _{10^{-}}$ transformed to satisfy the assumption of normality. Analyses on SL, BD, DWT, and gut fullness were conducted using the mean for each experimental tank on each sampling date. Multiple t-tests (least-squares means in Proc GLM; SAS Institute 1988) or Tukey's test (Proc GLM; SAS Institute 1988) were used to make subsequent comparisons among food treatments and sampling dates. Results from the multiple $t$-tests were compared to a p-value corrected for the number of food treatments and sampling dates compared [Bonferroni method, SL, BD, DWT: $p=0.05 /(5 \times 8)=0.0013$; SGR: $p=0.05 /(2 \times 4)=0.0063]$.

The influence of food treatment on the number of cod larvae surviving to Day 35 post-hatch, and those metamorphosing to juveniles by Day 50 post-hatch, was analyzed using a Kruskal-Wallis 1-way analysis of variance by ranks (Daniel 1978). A non-parametric analysis was used because the assumption of normality could not be met.

\section{RESULTS}

Results from the analyses of variance revealed a significant interaction between food treatment and larval 
Table 1 Results of least-squares means analyses, $t$-value (p-value in parentheses), comparing the standard length (mm) of cod larvae from 5 different food treatments (HF: high food throughout; LF: low food throughout; HF-LF: HF first $10 \mathrm{~d}$ post-hatch then LF; LF-HF: LF first 10 d post-hatch then HF; and NF: no food) at 5 d intervals from Days 15 to 35 post-hatch. There was no significant difference among food treatments between Days 0 and 10 post-hatch. "Significant difference between food treatments ( $p<0.0013, p$ corrected using the Bonferroni method)

\begin{tabular}{|c|c|c|c|c|c|}
\hline \multirow[t]{2}{*}{ Treatment } & \multicolumn{5}{|c|}{ Days post-hatch } \\
\hline & 15 & 20 & 25 & 30 & 35 \\
\hline $\mathrm{HF}$ and $\mathrm{HF}-\mathrm{LF}$ & $3.2(0.0030)$ & $3.8(0.0007)^{\circ}$ & $9.3(0.0001)^{\circ}$ & $9.1(0.0001)^{\circ}$ & $7.9(0.0001)^{\circ}$ \\
\hline HF and LF-HF & $4.0(0.0003)^{\circ}$ & $2.7(0.0120)$ & $8.7(0.0001)^{*}$ & $5.5(0.0001)^{\bullet}$ & $1.9(0.0640)$ \\
\hline HF and LF & $4.4(0.0001)^{*}$ & $5.6(0.0001)^{\circ}$ & $9.2(0.0001)^{*}$ & $11.1(0.0001)^{\circ}$ & $9.0(0.0001)^{\circ}$ \\
\hline HF and NF & $5.8(0.0001)^{\circ}$ & & & & \\
\hline $\mathrm{HF}-\mathrm{LF}$ and $\mathrm{LF}-\mathrm{HF}$ & $0.8(0.4330)$ & $1.1(0.2820)$ & $0.6(0.5510)$ & $3.6(0.0011)^{\circ}$ & $5.9(0.0001)^{\circ}$ \\
\hline HF-LF and LF & $1.1(0.2593)$ & $1.8(0.0801)$ & $0.1(0.8923)$ & $2.0(0.0514)$ & $1.1(0.2593)$ \\
\hline HF-LF and NF & $3.1(0.0042)$ & & & & \\
\hline LF-HF and LF & $0.4(0.7247)$ & $2.9(0.0074)$ & $0.5(0.6458)$ & $5.6(0.0001)^{\bullet}$ & $7.1(0.0001)^{\circ}$ \\
\hline LF-HF and NF & $2.5(0.0190)$ & & & & \\
\hline LF and NF & $2.2(0.0369)$ & & & & \\
\hline
\end{tabular}

Table 2. Results of least-squares means analyses, $t$-value (p-value in parentheses), comparing the body depth (mm) of cod Iarvae from 5 different food treatments (treatment identification as in Table 1) at $5 \mathrm{~d}$ intervals from Days 15 to 35 post-hatch. There was no significant difference among food treatments between Days 0 and 10 post-hatch. Significant difference between food treatments $(p<0.0013$, $p$ corrected using the Bonferroni method)

\begin{tabular}{|c|c|c|c|c|c|}
\hline Treatment & 15 & 20 & $\begin{array}{l}\text { ays post-hatch } \\
25\end{array}$ & 30 & 35 \\
\hline HF and HF-LF & $2.9(0.0055)$ & $4.9(0.0001)^{*}$ & $7.2(0.0001)^{\circ}$ & $7.2(0.0001)^{\circ}$ & $5.9(0.0001)^{*}$ \\
\hline $\mathrm{HF}$ and LF-HF & $2.9(0.0055)$ & $2.9(0.0055)$ & $5.5(0.0001)^{\bullet}$ & $3.4(0.0018)$ & $0.4(0.6732)$ \\
\hline $\mathrm{HF}$ and $\mathrm{LF}$ & $4.3(0.0002)^{\circ}$ & $5.1(0.0001)^{*}$ & $8.1(0.0001)^{*}$ & $8.5(0.0001)^{*}$ & $7.9(0.0001)^{\circ}$ \\
\hline $\mathrm{HF}$ and $\mathrm{NF}$ & $4.8(0.0001)^{\circ}$ & & & & \\
\hline $\mathrm{HF}-\mathrm{LF}$ and LF-HF & $0.0(1.0000)$ & $1.9(0.0648)$ & $1.7(0.0984)$ & $3.8(0.0006)^{\circ}$ & $5.5(0.0001)^{\circ}$ \\
\hline HF-LF and LF & $1.3(0.2110)$ & $0.2(0.8334)$ & $0.9(0.4010)$ & $1.3(0.2113)$ & $1.9(0.0643)$ \\
\hline HF-LF and NF & $2.4(0.0216)$ & & & & \\
\hline LF-HF and LF & $1.3(0.2114)$ & $2.1(0.0416)$ & $2.6(0.0167)$ & $5.1(0.0001)^{\bullet}$ & $7.5(0.0001)^{*}$ \\
\hline LF-HF and NF & $2.4(0.0211)$ & & & & \\
\hline LF and NF & $1.4(0.1748)$ & & & & \\
\hline
\end{tabular}

age (i.e. days post-hatch) for $\operatorname{SL}(F=8.29, \mathrm{df}=24,32$, $\mathrm{p}=0.0001), \mathrm{BD}(F=5.61, \mathrm{df}=24,32, \mathrm{p}=0.0001)$ and DWT $(F=6.38, \mathrm{df}=24,32, \mathrm{p}=0.0001)$ of cod larvae in our experiment. These results indicate that larval $\mathrm{SL}$, BD and DWT varied with larval age, and that the influence of age on these larval features was different depending on which food treatment the larvae were exposed to.

There was no significant difference among cod larvae reared under the 5 food treatments with respect to SL, BD or DWT when measured on Days 0,5 and 10 post-hatch. In contrast, larvae reared under a simulated match with their food source (i.e. HF treatment) were significantly larger in SL (Table 1) and BD (Table 2) by Day 15, and DWT (Table 3) by Day 20 post-hatch, as compared to those reared under mismatch conditions. This pattern continued until the end of the experiment, except for the complete mismatch condition (NF), in which all cod larvae were dead by Day 20 post-hatch, and for the LF-HF treatment (Figs, 1, 2 \& 3), for which there was no longer any significant difference between cod larvae reared under the LF-HF treatment and those reared under the HF condition by Day 35 post-hatch.

There was no significant difference in SL, BD or DWT among larvae from the 4 mismatch conditions up to $20 \mathrm{~d}$ post-hatch (Tables $1,2 \& 3$ ). This relationship among larvae from the HF-LF, LF-HF and LF conditions continued until Day 30 post-hatch, at which time the SL (Fig. 1), BD (Fig 2) and DWT (Fig. 3) of cod larvae reared under the LF-HF treatment became significantly greater (Tables $1,2 \& 3$ ). There was no significant difference in the SL, BD or DWT of larvae reared under the HF-LF and LF food treatments throughout the experiment (Tables $1,2 \& 3$ )

Larvae reared under the NF treatment showed an SGR of $0.35 \%$ for the time period 0 to $15 \mathrm{~d}$ post-hatch, 
Table 3. Results of least-squares means analyses, $t$-value (p-value in parentheses), comparing the dry wejght (mg) of cod larvae from 5 different food treatments (treatment identification as in Table 1) at 5 d intervals from Days 15 to 35 post-hatch. There was no significant difference among food treatments between Days 0 and 10 post-hatch. "Significant difference between food treatments ( $p<0.0013$, p corrected using the Bonferronı method)

\begin{tabular}{|c|c|c|c|c|c|}
\hline \multirow[t]{2}{*}{ Treatment } & \multicolumn{5}{|c|}{ Days post-hatch } \\
\hline & 15 & 20 & 25 & 30 & 35 \\
\hline $\mathrm{HF}$ and HF-LF & $1.0(0.3174)$ & $3.6(0.0011)^{\bullet}$ & $6.0(0.0001)^{\bullet}$ & $8.4(0.0001)^{\circ}$ & $4.9(0.0001)^{\circ}$ \\
\hline $\mathrm{HF}$ and LF-HF & $1.8(0.0760)$ & $2.1(0.0442)$ & $6.3(0.0001)^{\circ}$ & $4.6(0.0001)^{\bullet}$ & $0.8(04365)$ \\
\hline HF and LF & $1.4(0.1543)$ & $3.7(0.0008)^{\bullet}$ & $6.6(0.0001)^{\circ}$ & $9.5(0.0001)^{\bullet}$ & $8.3(0.0001)^{*}$ \\
\hline $\mathrm{HF}$ and NF & $2.8(0.0079)$ & & & & \\
\hline $\mathrm{HF}-\mathrm{LF}$ and LF-HF & $0.8(0.4200)$ & $1.5(0.1426)$ & $0.1(0.9890)$ & $3.8(0.0005)^{\circ}$ & $4.1(0.0002)^{\circ}$ \\
\hline HF-LF and LF & $0.4(0.6602)$ & $0.1(0.9890\}$ & $0.6(0.5713)$ & $1.1(0.2663)$ & $3.3(0.0023)$ \\
\hline HF-LF and NF & $2.0(0.0546)$ & & & & \\
\hline LF-HF and LF & $0.4(0.7125)$ & $1.6(0.1121)$ & $0.6(0.5800)$ & $4.9(0.0001)^{\circ}$ & $7.5(0.0001)^{\circ}$ \\
\hline LF-HF and NF & $1.3(0.1926)$ & & & & \\
\hline LF and NF & $1.6(0.1118)$ & & & & \\
\hline
\end{tabular}

following which they all died. This was an unexpected result, as with no food available, one would expect larvae to show a steady drop in weight over time, and, therefore, a negative SGR. Given that all larvae in the NF treatment died before Day 20 post-hatch, one possible explanation for our result may be that by Day 15 post-hatch only the largest larvae (i.e. ones with the greatest reserves) were still alive in the NF treatment.
This would appear to be the case, as the mean ( $\pm 1 \mathrm{SE}$ ) dry weight (mg) of larvae in the NF treatment at Day 15 post-hatch was $0.058( \pm 0.003)$ as compared to $0.055( \pm 0.007)$ at the time of hatch, resulting in our positive estimate of SGR.

When comparing SGR values for cod larvae reared under the other 4 food treatments, there was a significant interaction between food treatment and the time

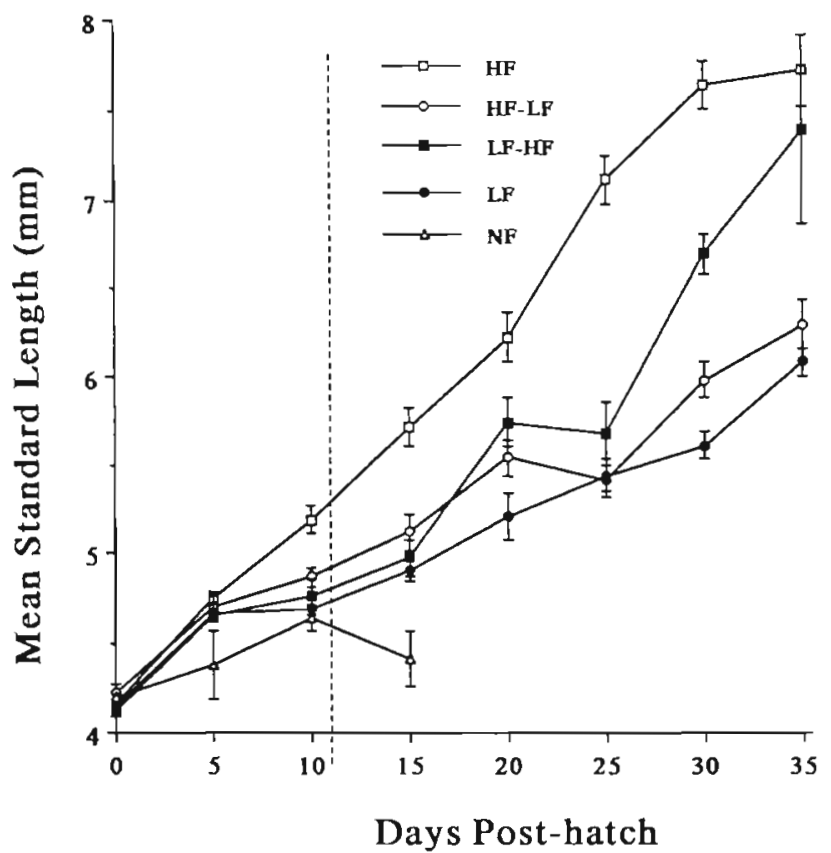

Fig. 1 Gadus morhua. Change over time in mean $( \pm 1 \mathrm{SE})$ standard length of Atlantic cod larvae reared under 5 different food treatments (HF: high food throughout; LF: low food throughout; HF-LF: HF first $10 \mathrm{~d}$ post-hatch then LF; LF-HF: LF first $10 \mathrm{~d}$ post-hatch then HF; and NF: no food). Dotted line indicates timing of switch in food level in HF-LF and LF-HF treatments

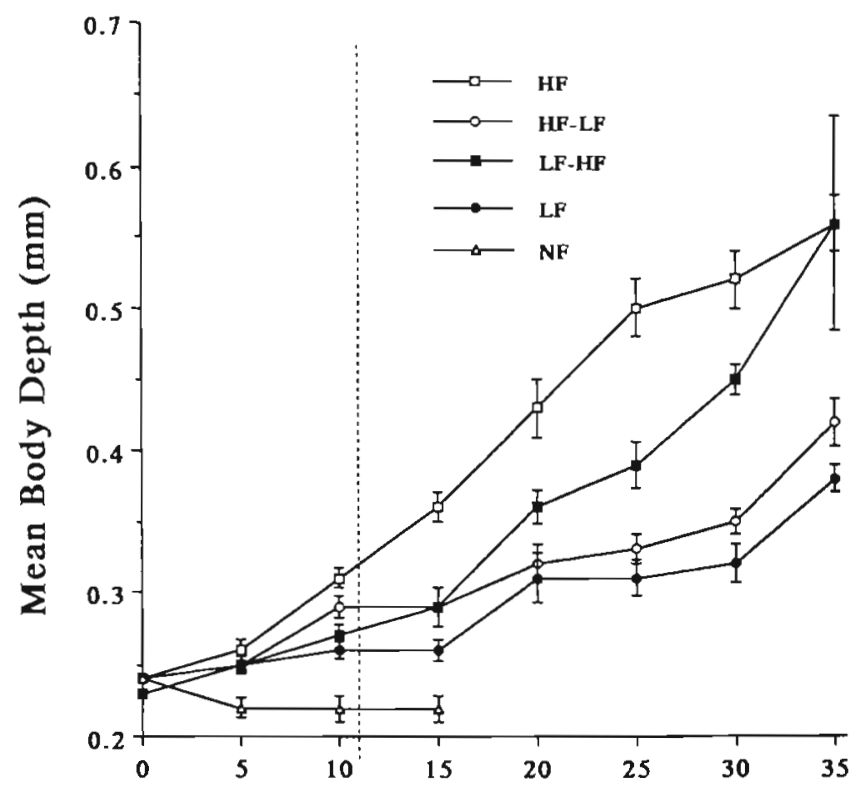

Days Post-hatch

Fig. 2. Gadus morhua. Change over time in mean $( \pm 1 \mathrm{SE})$ body depth of Atlantic cod larvae reared under 5 different food treatments (treatment identification as in Fig. 1). Dotted line indicates timing of switch in food level in HF-LF and LF-HF treatments 


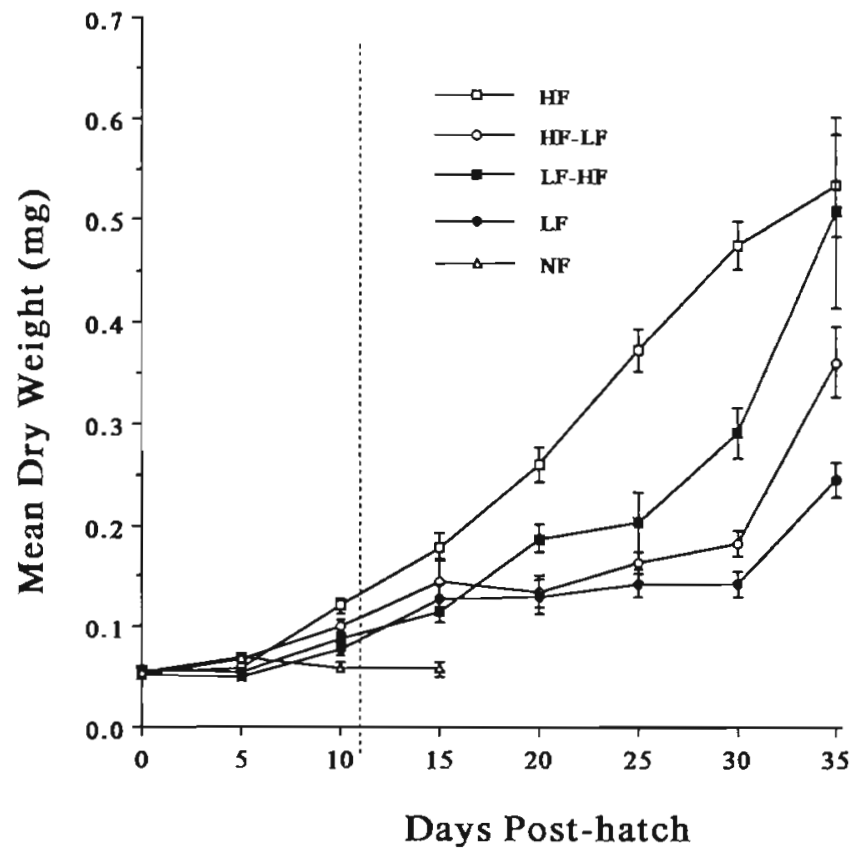

Fig. 3. Gadus morhua. Change over time in mean ( $\pm 1 \mathrm{SE}$ ) dry weight of Atlantic cod larvae reared under 5 different food treatments (treatment identification as in Fig. 1). Dotted line indicates timing of switch in food level in HF-LF and LF-HF treatments

interval over which SGR was calculated $(F=21.04, \mathrm{df}=$ $3,7, \mathrm{p}=0.0007$ ). Larvae exposed to the HF treatment showed a significantly higher SGR than those exposed to the LF treatment (Table 4). Larvae reared under the HF treatment had SGR values approximately 1.74 and 1.31 times those of larvae reared in the LF treatment over the time periods 0 to 10 and 10 to $35 \mathrm{~d}$ post-hatch, respectively (Fig. 4). The SGR of cod larvae reared under the HF-LF and LF-HF treatments changed with the change in food level (Table 4). The SGR of larvae in the HF-LF treatment started out comparable to that of larvae reared in the HF treatment. However, following the switch to $L F$ at $11 \mathrm{~d}$ post-hatch, the SGR of these larvae dropped to that of larvae reared at the LF level throughout the experiment (Fig. 4). Likewise, larvae in the LF-HF treatment started out with an SGR comparable to that of larvae in the LF treatment, but then showed an increase in their SGR following the switch in prey level, achieving a level comparable to that of larvae reared in the HF treatment (Fig. 4).

Prey items were present in the guts of cod larvae from all food treatments except NF from Day 5 posthatch. Both the day larvae were examined $(F=4.90$, $\mathrm{df}=6,28, \mathrm{p}=0.0015)$ and the food treatment to which larvae were exposed $(F=5.34, \mathrm{df}=3,28, \mathrm{p}=0.0049)$ had a significant effect on larval gut fullness. Subsequent analyses using a Tukey's test revealed no signif-

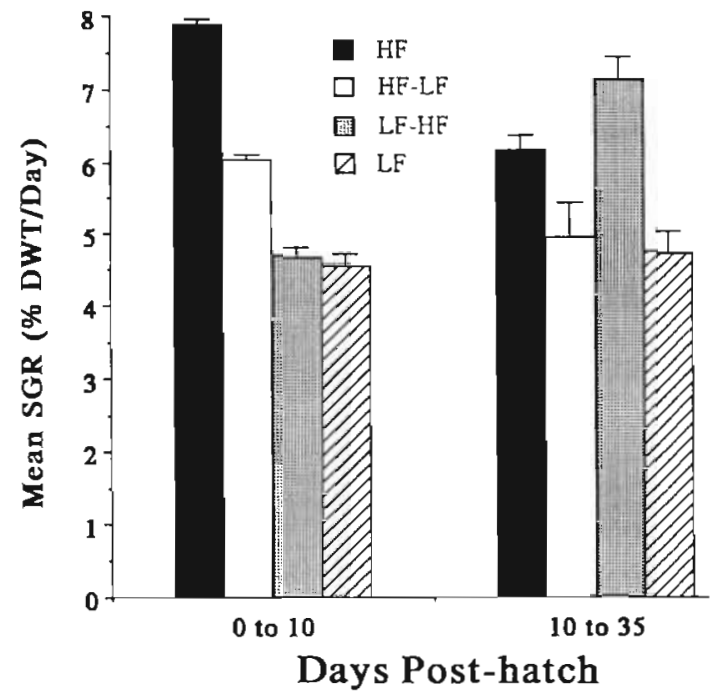

Fig. 4. Gadus morhua. Mean ( $\pm 1 \mathrm{SE}$ ) specific growth rate (SGR) of Atlantic cod larvae reared under 4 different food treatments (treatment identification as in Fig. 1). In treatments HF-LF and LF-HF, food levels changed from high to low and vice versa on Day 11 post-hatch

Table 4. Results of least-squares means analyses, $t$-value ( $p$-value in parentheses), comparing the growth rate $\%$ dry weight $\mathrm{d}^{-1}$ ) of cod larvae from 5 different food treatments (treatment identification as in Table 1) over the time periods of 0 to 10 , and 10 to $35 \mathrm{~d}$ post-hatch. "Significant difference between food treatments $(p<0.0063$, p corrected using the Bonferroni method\}

\begin{tabular}{|lcc|}
\hline \multirow{2}{*}{ Treatment } & \multicolumn{2}{c}{ Days post-hatch } \\
& 0 to 10 & 10 to 35 \\
\hline HF and HF-LF & $5.2(0.0013)^{\circ}$ & $3.3(0.0120)$ \\
HF and LF-HF & $9.1(0.0001)^{\circ}$ & $2.2(0.0641)$ \\
HF and LF & $9.4(0.0001)^{\circ}$ & $4.1(0.0048)^{\circ}$ \\
HF-LF and LF-HF & $3.9(0.0056)^{\circ}$ & $4.9(0.0017)^{\circ}$ \\
HF-LF and LF & $4.2(0.0039)^{\circ}$ & $0.7(0.5184)$ \\
LF-HF and LF & $0.3(0.7763)$ & $5.5(0.0009)^{\circ}$ \\
\end{tabular}

icant difference in mean gut fullness ( $\pm 1 \mathrm{SE}$ ) of larvae from the HF $(0.75 \pm 0.06)$ and LF-HF $(0.61 \pm 0.05)$ treatments or the LF $(0.52 \pm 0.03)$ and HF-LF $(0.52 \pm 0.04)$ treatments. However, these pairs of food treatments did differ significantly from each other, suggesting that a high density of prey did significantly increase prey capture success of cod larvae under our experimental conditions. These results are also consistent with those of the SGR values and the patterns of change recorded in SL, BD and DWT for cod larvae reared under the different food treatments.

Although not significantly different, the number of cod larvae surviving to Day 35 post-hatch $(H=4.23$, $\mathrm{df}=3, \mathrm{p}>0.1$, and the number of larvae having meta- 
Table 5. Total number, and percentage of original number introduced (3600 per treatment), of larval cod at Day 35 posthatch, and juveniles at Day 50 post-hatch, in the HF, LF, HFLF and LF-HF food treatments (treatment identification as in Table 1)

\begin{tabular}{|c|c|c|c|c|}
\hline \multirow[t]{2}{*}{ Treatment } & \multicolumn{2}{|c|}{ Day 35} & \multicolumn{2}{|c|}{ Day 50} \\
\hline & No. & $\%$ & No. & $\%$ \\
\hline $\mathrm{HF}$ & 198 & 5.50 & 76 & 2.11 \\
\hline $\mathrm{LF}$ & 9 & 0.25 & 1 & 0.03 \\
\hline HF-LF & 55 & 1.53 & 13 & 0.36 \\
\hline LF-HF & 125 & 3.47 & 30 & 0.83 \\
\hline
\end{tabular}

morphosed to juveniles by Day 50 post-hatch $(H=4.56$, $\mathrm{df}=3, \mathrm{p}>0.1$ ), were highest in food treatment HF, followed by LF-HF and HF-LF, and lowest in treatment LF (Table 5). The pattern of these results suggests that survival of cod larvae was enhanced under a food treatment simulating a match between the larvae and their prey. Finally, comparing the number of larvae surviving in the LF-HF, HF-LF, and LF food treatments (Table 5) suggests that the temporal pattern of a mismatch influences larval cod survival.

\section{DISCUSSION}

Results from this experiment, demonstrate that variation in various morphological parameters, prey capture success, specific growth rate (SGR), and survival of cod larvae are all influenced by the temporal overlap between larvae and their prey, and the resultant concentration of prey the larvae are exposed to during their development. For example, larvae exposed to an increase in prey concentration at $11 \mathrm{~d}$ post-hatch, showed the ability to compensate for an initially low SGR such that, by Day 35 post-hatch, these larvae had attained size equivalent to that of larvae exposed to this higher concentration of prey from Day 0 . Values of SGR calculated in this experiment are comparable to those reported in earlier studies examining the growth of both cod larvae (Laurence 1978, Laurence et al. 1981, Gamble \& Houde 1984) and the larvae of other temperate marine fish species (Buckley et al. 1987). As in our study, results from these studies showed that the SGR of larvae was significantly influenced by the concentration of prey to which the larvae were exposed during development. However, unlike these earlier studies, our results demonstrate that significant changes in the SGR of cod larvae can occur on a temporal scale within the larval life stage in response to variation in prey abundance.

Results from our study support the basic predictions of the match/mismatch hypothesis as related to the growth and survival of larval fish. For example, the hypothesis predicts good growth and survival in fish larvae when a match occurs between the peak in larval abundance and that of their prey (Cushing 1990). In our study, larval cod reared under match conditions (i.e. HF treatment) grew faster, achieved a larger sizeat-age, and showed a tendency for better survival then those reared under most of our simulated mismatch conditions

Cod larvae reared under our simulated mismatch condition of initial exposure to a low food concentration followed by a switch to high food conditions showed an intermediate response with respect to growth. Although these larvae initially grew like those in the other mismatch treatments, by the end of the experiment they had achieved a size equivalent to those reared under our match conditions. Larvae reared under this mismatch condition also showed a tendency towards improved survival as compared to those reared under our other mismatch treatments. While these results appear to contradict predictions of the match/mismatch hypothesis, they support the findings of various field studies and simulation models examining the hypothesis (Cushing 1990). For example, Fortier \& Gagne (1990) showed from field data that spring-spawned herring larvae (Clupea harengus) which hatched several weeks prior to the peak in plankton production (i.e. similar to our LF-HF conditions) showed good survival as compared to autumnspawned larvae which showed high mortality as their food stocks ran out (i.e. HF-LF conditions). In their mesocosm study on variability in feeding conditions and the growth and survival of cod larvae, van der Meeren \& Naess (1993) found no significant difference in survival or the final growth rate achieved by larvae which initially started out under conditions of low food levels, followed by an increase to a high level, and those reared under a high level throughout. Based on their results, these authors concluded that lower growth due to food limitations during early larval development may not necessarily result in increased mortality. In their work in Dabob Bay (Washington, USA) Bollens et al. (1992) found that the annual peak in abundance of a variety of larval fishes preceded the peak abundance of their prey. Based on their data, these authors constructed a simulation model to predict 'optimal' spawning time, the optimization criteria being to minimize the time required by larvae to attain a certain weight or critical size. Results from this model showed that, within limits, by advancing spawning time prior to the peak in prey availability the criteria of the model could be met. Taken together, results from these various studies and ours suggest that a mismatch between the peak in larval abundance and that of their prey may not necessarily result in poor larval growth 
and survival. Instead, it appears that the temporal positioning of the mismatch may be very important.

Based on their results, van der Meeren \& Naess (1993) concluded that cod larvae appear to have a high potential for growth independent of limited growth lapses early in development, a potential which can be realized when energetically favourable food becomes abundant. Similar 'compensatory' growth in response to an increased food supply has been reported for adult Atlantic cod (Pedersen \& Jobling 1989), larval herring (Pedersen et al. 1990), as well as various other organisms (e.g. Wilson \& Osbourn 1960). Results from our LFHF treatment support those of van der Meeren \& Naess (1993), in that cod larvae reared in this treatment seemed to show this compensatory growth response

From their analysis of the relationship between temperature and survival of first-feeding cod larvae, Ellertsen et al. (1989) concluded that both extremely cold and warm years resulted in poor survival and recruitment of cod. This was attributed to the relationship between temperature and reproduction by the copepod Calanus finmarchicus, the early life stages of which are the primary prey of the cod larvae. Cold years result in a delay in copepod reproduction (i.e. our LF-HF condition), while warm years produce an earlier peak in prey abundance relative to that of the cod larvae (i.e. our HF-LF condition). While our data are consistent with the predictions for warm years, this does not appear to be the case for cold years. However, the results reported by Ellertsen et al. (1989), and those from other field studies, present the potential impact of a match/mismatch with respect to the entire year's output of eggs. In contrast, our experiment mimics the influence of a match/mismatch on a batch of eggs spawned at one time during the spawning season. Therefore, while our results may reflect the outcome of a match/mismatch for an entire cohort of larvae, this would only be true under certain conditions (e.g. peak in prey abundance precedes any spawning by fish). However, given an extended spawning season in cod, we would predict that larvae from at least some batches of eggs within this spawning season would be confronted with match/mismatch conditions similar to those tested in our experiment every year Predicting the effect of a match/mismatch on recruitment, therefore, should be related to how closely the conditions faced by most of the larvae within the cohort are to those simulated for a batch of eggs in our study. Our conclusion would seem to be supported by that of Mertz \& Myers (1994), that variation in spawning duration among subpopulations of Atlantic cod can affect the degree of overlap between larvae and their prey, and, therefore, recruitment variability.

In this study, food levels and the timing of the switch in food abundance were chosen in an attempt to insure sufficient survival of cod larvae to allow comparisons among food treatments to be made. We realize, for example, that reducing prey abundance in low food treatments and extending the time larvae were exposed to this low food level prior to experiencing a switch to a high food level could dramatically alter our results. It is exactly these types of manipulations which are needed in future studies if we are to gain an even better understanding of the influence a match/mismatch may have on the growth and survival of larval fishes and of the potential of fish larvae to withstand food limitations in the early stages of their development.

Finally, the match/mismatch hypothesis, and our study, focuses primarily on the influence temporal variation in prey abundance may have on growth and survival in larval fishes. While food availability is certainly important, various other factors are also known to influence the growth and survival of larval fishes, including predation on larvae, food quality, and competition. For example, studies have suggested that rapid growth and a larger body size-at-age in larval fish significantly increases their chances of survival to the juvenile stage (Miller et al. 1988). This being the case, our results would appear to support the prediction of the match/mismatch hypothesis that a match should result in increased larval survival and recruitment. However, results from recent studies investigating factors affecting predation risk to larval fishes call into question whether a larger body size-at-age does necessarily increase larval survival (Litvak \& Leggett 1992, Pepin et al. 1992, Gotceitas \& Brown 1993). Given that a number of factors are likely to significantly influence the final outcome (i.e. recruitment) of a match or mismatch between larvae and their prey, studies looking at the interplay among these various factors are needed to better understand the contribution a match or mismatch may have on larval survival and recruitment.

Acknowledgements. We thank S. Fraser and 3 anonymous reviewers for their helpful comments on this manuscript. This research was supported through funding by OPEN - the Ocean Production Enhancement Network - one of the 15 Networks of the Centres of Excellence supported by the Government of Canada. This is Ocean Sciences Centre contribution no. 254.

\section{LITERATURE CITED}

Blaxter JHS (1986) Development of sense organs and behaviour of teleost larvae with special reference to feeding and predator avoidance. Trans Am Fish Soc 115:98-114

Bollens SM, Frost BW, Schwannger HR, Davis CS, Way KJ, Landsteiner MC (1992) Seasonal plankton cycles un a temperate fjord and comments on the match-mismatch hypothesis. J Plankton Res 14:1279-1305 
Brander K (1992) A re-examination of the relationship between cod recruitment and Calanus finmarchicus in the North Sea. ICES mar Sci Symp 195:393-401

Buckley LJ, Halavik TA, Smıgrelski AS, Laurence GC (1987) Growth and survival of the larvae of three species of temperate marine fishes reared at discrete prey densities. Am Fish Soc Symp 2:82-92

Cui Y, Liu J (1990) Comparison of energy budget among slx teleosts - III. Growth rate and energy budget. Comp Biochem Physiol 97 A:381-384

Cushing DH (1990) Plankton production and year-class strength in fish populations: an update of the match/mismatch hypothesis. Adv mar Biol 26:249-293

Daniel WW (1978) Applied nonparametric statistıcs. Houghton Mifflin Company, Boston

Duray M, Kohno $H$ (1988) Effects of continuous lighting on growth and survival of first-feeding larval rabbitfish, Siganus guttatus. Aquaculture 72:73-79

Ellertsen B, Fossum P, Solemdal P, Sundby S (1989) Relation between temperature and survival of eggs and first-feeding larvae of northeast Arctic cod (Gadus morhua L.). Rapp Pv Réun Cons int Explor Mer 191:209-219

Fortier L, Gagne JA (1990) Larval herring (Clupea harengus) dispersion, growth, and survival in the St. Lawrence estuary: match/mismatch or membership/vagrancy? Can J Fish Aquat Sci 47:1898-1912

Frank KT (1988) Independent distribution of fish larvae and their prey: natural paradox or sampling artifact? Can J Fish Aquat Sci 45:48-59

Gamble JC, Houde ED (1984) Growth, mortality and feeding of cod (Gadus morhua L.) larvae in enclosed water columns and in laboratory tanks. In: Dahl E, Danielssen DS, Moksness E, Solemdal P (eds) The propagation of cod Gadus morhua L. Flodevigen rapportser, 1, Institute of Marine Research, Flodevigen Biological Station, Arendal, p 123-143

Gotceitas V, Brown JA (1993) Risk of predation to fish larvae in the presence of alternative prey: effects of prey size and number. Mar Ecol Prog Ser 98:215-222

Hawkins AD, Soofiani NM, Smith GW (1985) Growth and feeding of juvenile cod (Gadus morhua L.). J Cons int Explor Mer 42:11-32

Houde ED (1987) Fish early life dynamics and recruitment variability. Am Fish Soc Symp 2:17-29

Howell BR (1984) The intensive rearing of Juvenile cod, Gadus morhua L. In: Dahl E, Danielssen DS, Moksness E, Solemdal P (eds) The propagation of cod Gadus morhua L. Flødevigen rapportser 1 (1984):657-675

Hunter RJ, Thomas GL (1974) Effect of prey distribution and density on the searching and feeding behaviour of larval

This article was submitted to the editor anchovy Engraulis mordax Girard. In: Blaxter JHS (ed) The early life history of fish. Springer Verlag, New York, p $559-574$

Laurence GC (1978) Comparative growth, respiration and delayed feeding abilities of larval cod (Gadus morhua) and haddock (Melanogrammus aeglefinus) as influenced by temperature during laboratory studies. Mar Biol 50:1-7

Laurence GC, Smigielski A.S, Halavık. TA, Burns BR (1981) Implications of direct competition between larval cod (Gadus morhua) and haddock (Melanogrammus aeglefinus) in laboratory growth and survival studies at different food densities. Rapp Pv Réun Cons int Explor Mer 178: $304-311$

Litvak MK, Leggett WC (1992) Age and size-selective predation on larval fishes: the bigger-is-better hypothesis revisited. Mar Ecol Prog Ser 81:13-24

Mertz G. Myers RA (1994) Match/mismatch predictions of spawning duration versus recruitment variability. Fish Oceanogr 3:236-245

Miller TJ, Crowder LB, Rice JA, Marschall EA (1988) Larval size and recruitment mechanisms in fishes: towards a conceptual framework. Can J Fish Aquat Sci 45: $1657-1670$

Pedersen T, Jobling M (1989) Growth rates of large, sexually mature cod, Gadus morhua, in relation to condition and temperature during an annual cycle. Aquaculture 81 161-168

Pedersen BH, Ugelstad I, Hjelmeland K (1990) Effects of a transitory, low food supply in the early life of larval herning (Clupea harengus) on mortality, growth and digestive capacity. Mar Biol 107:61-66

Pepin P, Shears TH, de Lafontaine $Y$ (1992) Significance of body size to the interaction between larval fish (Mallotus villosus) and a vertebrate predator (Gasterosteus aculeatus). Mar Ecol Prog Ser 81:1-12

Runge JA (1988) Should we expect a relationship between primary production and fisheries? The role of copepod dynamics as a filter of trophic variability. Hydrobiologia 167/168:61-71

SAS Institute (1988) SAS/STAT user's guide, release 6.03 edn. SAS Institute, Inc, Cary, NC

Thompson AB, Harrop RT (1991) Feeding dynamics of fish larvae on Copepoda in western Irish Sea, with particular reference to cod Gadus morhua. Mar Ecol Prog Ser 68: $213-223$

van der Meeren T, Naess T (1993) How does cod (Gadus morhual cope with variability in feeding conditions during early larval stages? Mar Biol 116:637-647

Wilson PN, Osbourn DF (1960) Compensatory growth after undernutrition in mammals and birds. Biol Rev 35:324-363

Manuscript first received: January 31, 1995

Revised version accepted: July 13,1995 